\title{
Erratum: Genomic variants in mouse model induced by azoxymethane and dextran sodium sulfate improperly mimic human colorectal cancer
}

\author{
Qingfei Pan ${ }^{1,2}$, Xiaomin Lou ${ }^{1}$, Ju Zhang ${ }^{1}$, Yinghui Zhu ${ }^{1}$, Fuqiang Li $\mathbb{D}^{3}$, Qiang Shan ${ }^{1}$, Xianwei \\ Chen ${ }^{1}$, Yingying Xie ${ }^{1}$, Siyuan $\mathrm{Su}^{1}$, Hanfu Wei ${ }^{4}$, Liang Lin $^{3}$, Lin Wu ${ }^{1,2}$ \& Siqi Liu ${ }^{1,2,3}$ \\ Scientific Reports 7:25; doi:10.1038/s41598-017-00057-3; Article published online 07 February 2017
}

The original version of this Article stated an incorrect publication date. In addition, the Acknowledgments section of this Article was incomplete:

This project is financially supported by the National Natural Science Foundation of China (NO. 91131009). We thank Beijing Protein Innovation for their help in animal model establishment, BGI-Shenzhen for exome capturing and sequencing, and Beijing Institute of Genomics for the validation of somatic mutations.

Now reads:

This project is partially supported by the National Natural Science Foundation of China (NO. 91131009 and NO. 81372601), and the Fundamental \& Advanced Research Project of Chongqing, China (NO. cstc2013jcyjC00001). We thank Beijing Protein Innovation for their help in animal model establishment, BGI-Shenzhen for exome capturing and sequencing, and Beijing Institute of Genomics for the validation of somatic mutations.

These errors have now been corrected in the HTML and PDF versions of the Article.

(i) Open Access This article is licensed under a Creative Commons Attribution 4.0 International License, which permits use, sharing, adaptation, distribution and reproduction in any medium or format, as long as you give appropriate credit to the original author(s) and the source, provide a link to the Creative Commons license, and indicate if changes were made. The images or other third party material in this article are included in the article's Creative Commons license, unless indicated otherwise in a credit line to the material. If material is not included in the article's Creative Commons license and your intended use is not permitted by statutory regulation or exceeds the permitted use, you will need to obtain permission directly from the copyright holder. To view a copy of this license, visit http://creativecommons.org/licenses/by/4.0/.

(C) The Author(s) 2017

${ }^{1}$ CAS Key Laboratory of Genome Sciences and Information, China Gastrointestinal Cancer Research Center, Beijing Institute of Genomics, Chinese Academy of Sciences, Beijing, China. ${ }^{2}$ Sino-Danish Center for Education and Research, University of Chinese Academy of Sciences, Beijing, China. ${ }^{3}$ BGI-Shenzhen, Shenzhen, China. ${ }^{4}$ Beijing Protein Innovation, Beijing, China. Correspondence and requests for materials should be addressed to L.W. (email: wul@big.ac.cn) or S.L. (email: siqiliu@big.ac.cn) 